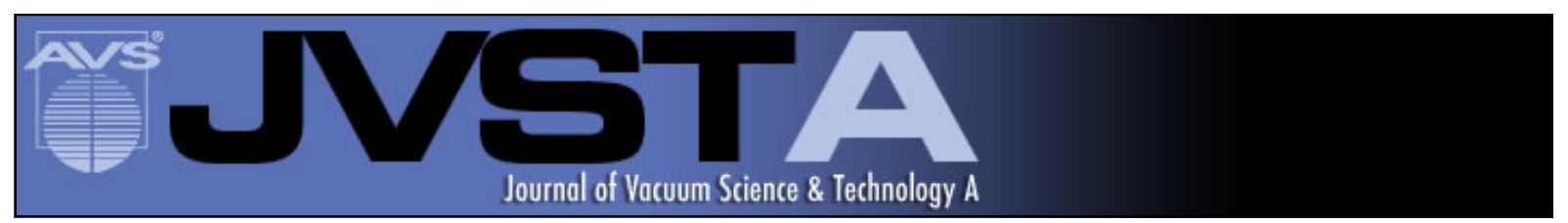

\title{
Plasma enhanced atomic layer deposition of zinc sulfide thin films
}

Jakob Kuhs, Thomas Dobbelaere, Zeger Hens, and Christophe Detavernier

Citation: Journal of Vacuum Science \& Technology A 35, 01B111 (2017); doi: 10.1116/1.4967724

View online: http://dx.doi.org/10.1116/1.4967724

View Table of Contents: http://scitation.aip.org/content/avs/journal/jvsta/35/1?ver=pdfcov

Published by the AVS: Science \& Technology of Materials, Interfaces, and Processing

\section{Articles you may be interested in}

Optical characteristics of nanocrystalline AlxGa1-xN thin films deposited by hollow cathode plasma-assisted atomic layer deposition

J. Vac. Sci. Technol. A 32, 031508 (2014); 10.1116/1.4870381

Growth and structure of $\mathrm{ZnO}$ thin films on polar $(\sqrt{3} \times \sqrt{3}) \mathrm{R} 30^{\circ}$ reconstructed and unreconstructed $\mathrm{MgO}(111)$ surfaces by atomic layer deposition

J. Vac. Sci. Technol. A 31, 021504 (2013); 10.1116/1.4791667

Atomic layer deposition of Al-doped $\mathrm{ZnO}$ thin films

J. Vac. Sci. Technol. A 31, 01A109 (2013); 10.1116/1.4757764

Growth morphology and electrical/optical properties of Al-doped $\mathrm{ZnO}$ thin films grown by atomic layer deposition J. Vac. Sci. Technol. A 30, 021202 (2012); 10.1116/1.3687939

Growth characteristics, material properties, and optical properties of zinc oxysulfide films deposited by atomic layer deposition

J. Vac. Sci. Technol. A 30, 01A135 (2012); 10.1116/1.3664758

\section{HDDEN}

\section{Instruments for Advanced Science}

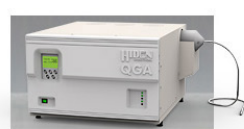

Gas Analysis

dynamic measurement of reaction gas streams catalysis and thermal analysis

molecular beam studies

, dosolled becies probes

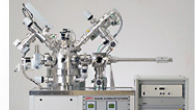

Surface Science

UHVTPD

SIMS point detection in ion beam etch elemental imaging - surface mapping

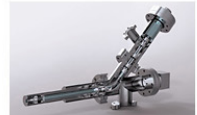

Plasma Diagnostics plasma source characterization etch and deposition process reaction kinetic studies analysis of neutral and radical species

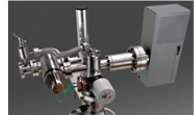

Vacuum Analysis of process gases reactive sputter process contro , vacuum diagnostics acuum caating process monitorin partial pressure measurement and control 


\title{
Plasma enhanced atomic layer deposition of zinc sulfide thin films
}

\author{
Jakob Kuhs and Thomas Dobbelaere \\ Department of Solid State Sciences, CoCooN, Ghent University, Krijgslaan 281/S1, 9000 Ghent, Belgium \\ Zeger Hens \\ Department of Inorganic and Physical Chemistry, PCN, Ghent University, Krijgslaan 281/S3, 9000 Ghent, \\ Belgium \\ Christophe Detavernier ${ }^{\mathrm{a})}$ \\ Department of Solid State Sciences, CoCooN, Ghent University, Krijgslaan 281/S1, 9000 Ghent, Belgium
}

(Received 6 September 2016; accepted 27 October 2016; published 15 November 2016)

\begin{abstract}
Zinc sulfide thin films were deposited by plasma enhanced atomic layer deposition (PE-ALD) using diethylzinc and $\mathrm{H}_{2} \mathrm{~S} / \mathrm{Ar}$ plasma. The growth characteristics were studied in situ with spectroscopic ellipsometry and ex situ with x-ray reflectometry. The growth was linear and selflimited. Furthermore, it was demonstrated that the growth per cycle was less temperature dependent for the PE-ALD process compared to the thermal process. $\mathrm{ZnS}$ thin film properties were investigated ex situ using x-ray photoelectron spectroscopy, x-ray diffraction, ultraviolet/visible optical spectroscopy, and atomic force microscopy. The as-deposited films were crystalline with a transmittance of $>90 \%$ and a band gap of $3.49 \mathrm{eV}$. ZnS films deposited by PE-ALD were smoother than films deposited by thermal ALD. The plasma enhanced ALD process may have an advantage for ALD of ternary compounds where different temperature windows have to be matched or for applications where a smooth interface is required. (C) 2016 American Vacuum Society.

[http://dx.doi.org/10.1116/1.4967724]
\end{abstract}

\section{INTRODUCTION}

Zinc sulfide is a nontoxic wide band gap II-VI semiconductor which can be doped n- and p-type. Two main crystalline forms exist: the cubic zinc blend structure and the hexagonal wurtzite. The main applications for zinc sulfide are as luminescent host material in, e.g., thin film electroluminescent displays, and as optical windows or coatings in the near infrared region. Recently, $\mathrm{ZnS}$ attracted much attention for its application as a Cd-free buffer layer in CIGS thin film solar cells, ${ }^{1,2}$ as a potential material for p-type transparent conductive layers (TCL) ${ }^{3,4}$ and in field effect transistors. ${ }^{5,6}$ Atomic layer deposition (ALD) is an ideal deposition technique for these applications since they require a high degree of control over the layer thickness as well as conformal layers.

ALD is a self-limited deposition method that is characterized by alternating exposure of the growing film to different chemical precursors, resulting in the sequential deposition of (sub)monolayers over the exposed sample surface. ${ }^{7,8}$ The self-limiting nature of the vapor-solid reactions ensures pinhole free inorganic coatings with a precise thickness controlled at the atomic scale and a superb conformality onto large scale substrates with complex topologies.

The first ZnS ALD processes reported in the $1970 \mathrm{~s}^{9}$ used elemental zinc and sulfur as precursors. These processes require high source temperatures and therefore high deposition temperatures of $500^{\circ} \mathrm{C}$ which limits the potential applications. Shortly after, the atomic precursors were substituted for molecular ones such as $\mathrm{H}_{2} \mathrm{~S}$ and halides like $\mathrm{ZnCl}_{2}$ (Refs. 10-12) or $\mathrm{ZnI}_{2} .{ }^{13}$ Although having already lower deposition temperatures of around $300-400^{\circ} \mathrm{C}$, these temperatures are

${ }^{a)}$ Electronic mail: christophe.detavernier@ugent.be still too high for some applications. ${ }^{14}$ Furthermore, halide precursors have the disadvantage that they leave impurities in the ZnS films. ${ }^{15}$ Therefore, metalorganic precursors such as diethylzinc (DEZ) and dimethylzinc were started to be investigated as an alternative. These precursors typically have a wide temperature stability and a high vapor pressure resulting in a large temperature range and high growth per cycle (GPC), respectively. ${ }^{14}$ However, using the thermal DEZ and $\mathrm{H}_{2} \mathrm{~S}$ process, a monotonically decreasing GPC is observed with increasing temperature. ${ }^{15-18}$

Apart from $\mathrm{H}_{2} \mathrm{~S}$ and elemental $\mathrm{S}$, only a few alternatives for the S source in ZnS ALD were investigated. One promising approach is the in situ production of $\mathrm{H}_{2} \mathrm{~S}$ from thioacetamide. ${ }^{16}$ In this study, we report a novel plasma enhanced ALD process for ZnS using DEZ and an argon diluted hydrogen sulfide plasma $\left[\left(\mathrm{H}_{2} \mathrm{~S} / \mathrm{Ar}\right)^{*}\right]$ as an alternative $\mathrm{S}$ source. In comparison to the thermal DEZ and $\mathrm{H}_{2} \mathrm{~S}$ process, this new process showed less temperature sensitivity, and a high GPC was obtained for temperatures up to $300^{\circ} \mathrm{C}$. The structural and optical properties of plasma enhanced atomic layer deposition (PE-ALD) ZnS were compared to thermal ALD ZnS.

\section{EXPERIMENTAL DETAILS}

Zinc sulfide thin films were deposited in a home-built pump-type ALD reactor by using DEZ ( $>95 \%$, Strem Chemicals) in combination with $\mathrm{H}_{2} \mathrm{~S} / \mathrm{Ar}$ plasma as reactants. The DEZ precursor was stored in a stainless steel bottle at room temperature while the DEZ precursor line was heated to $50^{\circ} \mathrm{C}$. The substrates were $\mathrm{Si}(100)$ wafers covered with $100 \mathrm{~nm}$ thermally grown $\mathrm{SiO}_{2}$ or quartz for optical transmission measurements. To estimate the conformality of the process, 
$\mathrm{SiO}_{2}$ covered micropillars were used as a substrate. Argon diluted $\mathrm{H}_{2} \mathrm{~S}$ plasma was used instead of pure $\mathrm{H}_{2} \mathrm{~S}$ plasma in order to minimize the exposure of the ALD reactor to the highly reactive $\mathrm{S}$ radicals. The plasma was generated remotely from the substrate by radio frequency inductive coupling at $200 \mathrm{~W}$. The substrate temperature was varied from 60 to $300^{\circ} \mathrm{C}$. A standard ALD cycle consisted of $5 \mathrm{~s}$ precursor pulses followed by $25 \mathrm{~s}$ of pumping.

The $\mathrm{ZnS}$ thin film growth rate was monitored in situ by spectroscopic ellipsometry [(SE) J. A. Woollam M-2000] using a library model based on an oscillator model. This model was verified by measuring several $\mathrm{ZnS}$ thin films $e x$ situ with $\mathrm{x}$-ray reflectivity (XRR) and comparing the obtained film thickness with the SE measurements. Even during the first cycles of the film growth, good quality fits to the ellipsometric data were obtained.

$\mathrm{X}$-ray photoelectron spectroscopy (XPS) was used to determine the chemical composition of the deposited $\mathrm{ZnS}$ films. All measurements were performed in-house with a Theta Probe system from Thermo Scientific using $\mathrm{Al} \mathrm{K \alpha}$ $\mathrm{x}$-rays generated at $15 \mathrm{kV}$ and focused to a spot size of $0.3 \mathrm{~mm}$ by an MXR1 monochromator gun. In order to remove surface contamination, the samples were etched with $\mathrm{Ar}^{+}$ions at an acceleration voltage of $3 \mathrm{keV}$ and a current of $2 \mu \mathrm{A}$. The obtained binding energies (BE) were calibrated by using a $\mathrm{BE}$ of $284.6 \mathrm{eV}$ for the carbon peak. ${ }^{19}$

$\mathrm{X}$-ray diffraction (XRD) and $\mathrm{x}$-ray reflectivity (XRR) patterns were obtained with a Bruker D8 Discover using a $\mathrm{Cu}$ $\mathrm{K} \alpha \mathrm{x}$-ray source and a linear detector.

The optical properties of $\mathrm{ZnS}$ were measured in the UV/ Vis range with a spectrophotometer (Perkin Elmer Lambda 950) on quartz substrates. Transmittance spectra were measured in the range of $250-1000 \mathrm{~nm}$. The measured transmittance was divided by the transmittance of the bare quartz substrate in order to obtain only the transmittance of the $\mathrm{ZnS}$ film.

Scanning electron microscopy (SEM) and energy-dispersive $\mathrm{x}$-ray spectroscopy (EDX) measurements were performed in an FEI SEM at an energy of $12 \mathrm{keV}$ and a silicon-drift detector was used.

The surface morphology of the films was determined by atomic force microscopy (AFM) on a Bruker Dimension Edge system operating in tapping mode in air. The root mean square (RMS) roughness was calculated from $3 \times 3 \mu \mathrm{m}$ scans.

The plasma enhanced process was characterized using optical emission spectroscopy and mass spectrometer analysis. An Ocean Optics QE Pro spectrometer coupled to the plasma column (soda-lime glass) by an optical fiber was used to obtain optical emission spectra. Mass spectrometry was carried out in situ during the ALD process with a HPR30 mass spectrometer from Hiden.

\section{RESULTS AND DISCUSSION}

\section{A. ALD growth characterization}

The linearity and growth characteristics of the thermal ALD and PE-ALD ZnS processes were studied at 65 and

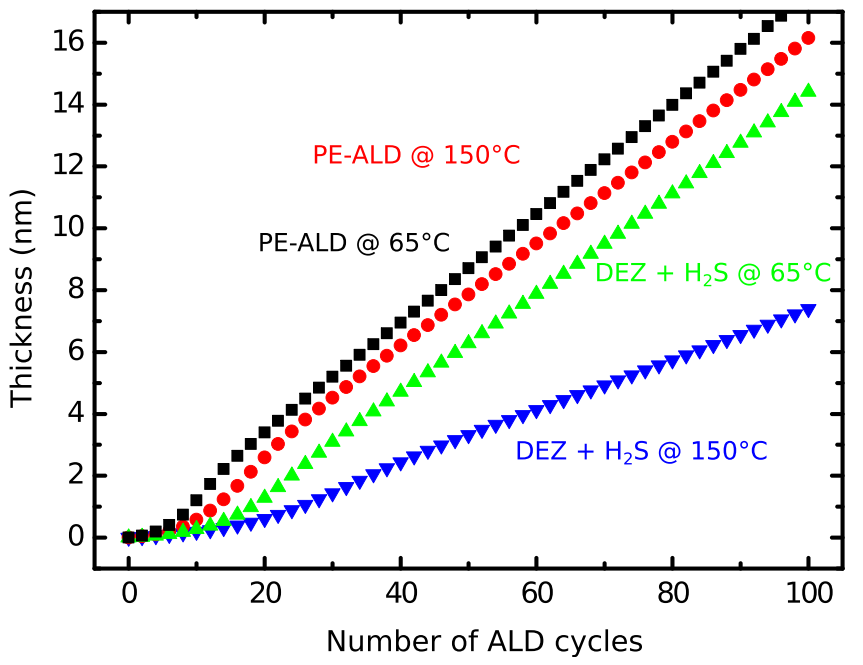

FIG. 1. (Color online) Thickness of different $\mathrm{ZnS}$ thin films deposited at 65 and $150{ }^{\circ} \mathrm{C}$ as a function of the number of ALD cycles.

$150^{\circ} \mathrm{C}$ on $\mathrm{Si}$ substrates covered with $100 \mathrm{~nm}$ thermally grown $\mathrm{SiO}_{2}$. The $\mathrm{ZnS}$ film thickness was calculated from in situ spectral ellipsometry measurements performed after completed ALD cycles. This is displayed as a function of ALD cycles in Fig. 1. For both processes, the growth was linear after a short nucleation time. It can be seen that the $\mathrm{H}_{2} \mathrm{~S} / \mathrm{Ar}$ plasma enhanced process nucleated slightly earlier than the thermal process. As opposed to the thermal ALD process, the PE-ALD process showed only a minor dependency on the deposition temperature.

The ALD windows of the thermal and PE-ALD ZnS processes were determined by measuring the GPC with in situ spectroscopic ellipsometry for different substrate temperatures from 65 to $300^{\circ} \mathrm{C}$ (Fig. 2). The thermal and PE-ALD processes had the same maximal GPC of $1.7 \AA$ /cycle at a temperature of $65^{\circ} \mathrm{C}$ which corresponds to a growth rate of approximately 0.5 monolayers/cycle using the lattice dimension of $3.12 \AA$ for the cubic [111] growth direction. ${ }^{17}$ The thermal processes showed a decrease in GPC for increasing

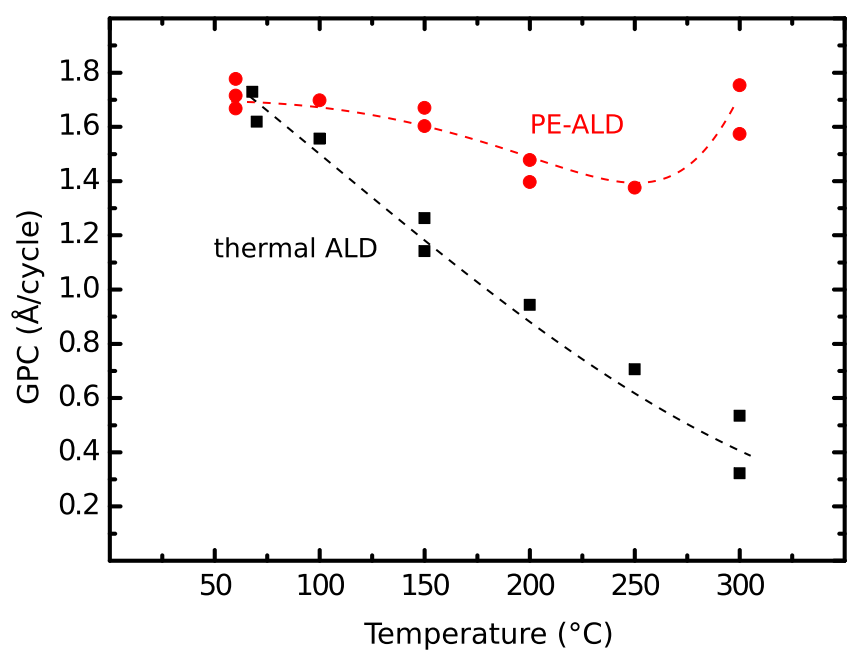

FIG. 2. (Color online) GPC as a function of the deposition temperature for thermal and PE-ALD of $\mathrm{ZnS}$. Dashed lines are a guide to the eye. 
deposition temperature of more than $70 \%$ over the investigated temperature range which is in accordance to the earlier reports. ${ }^{15-18}$ In contrast, only a minor temperature dependency for the PE-ALD process was found. The GPC of the PE-ALD process dropped by $20 \%$ for a deposition temperature of $250{ }^{\circ} \mathrm{C}$. At higher temperatures, the GPC started to rise again. This may be related to the self-decomposition of the DEZ precursor, although this should normally only start at around $320^{\circ} \mathrm{C}^{20}$ The increased GPC of the PE-ALD process in comparison with the thermal one can lead to a better device integration or better matching of temperature windows for ALD of ternary compounds. ${ }^{21,22}$

The saturation behavior of the PE-ALD process was studied at a temperature of 65 and $150{ }^{\circ} \mathrm{C}$ by measuring the GPC with in situ spectroscopic ellipsometry while varying the pulse time of the precursors and reactants. Figure 3 shows the GPC as a function of the pulse time of DEZ and $\left(\mathrm{H}_{2} \mathrm{~S} /\right.$ $\mathrm{Ar})^{*}$ for a deposition temperature of (a) $65^{\circ} \mathrm{C}$ and (b) $150^{\circ} \mathrm{C}$. The PE-ALD process at $65^{\circ} \mathrm{C}$ saturates after approximately $3 \mathrm{~s}$ while the PE-ALD at $150^{\circ} \mathrm{C}$ saturates after approximately $4-5 \mathrm{~s}$.

Optical emission spectroscopy was used to obtain an overview over the reactive species present in the PE-ALD process. Figure 4(a) shows the optical emission spectrum of the $\mathrm{H}_{2} \mathrm{~S} / \mathrm{Ar}$ plasma. Since all the features related to the $\mathrm{H}_{2} \mathrm{~S}$ disappeared in the high intensity $\mathrm{Ar}$ spectrum, a pure $\mathrm{H}_{2} \mathrm{~S}$ plasma was investigated [Fig. 4(b)]. The spectrum contained
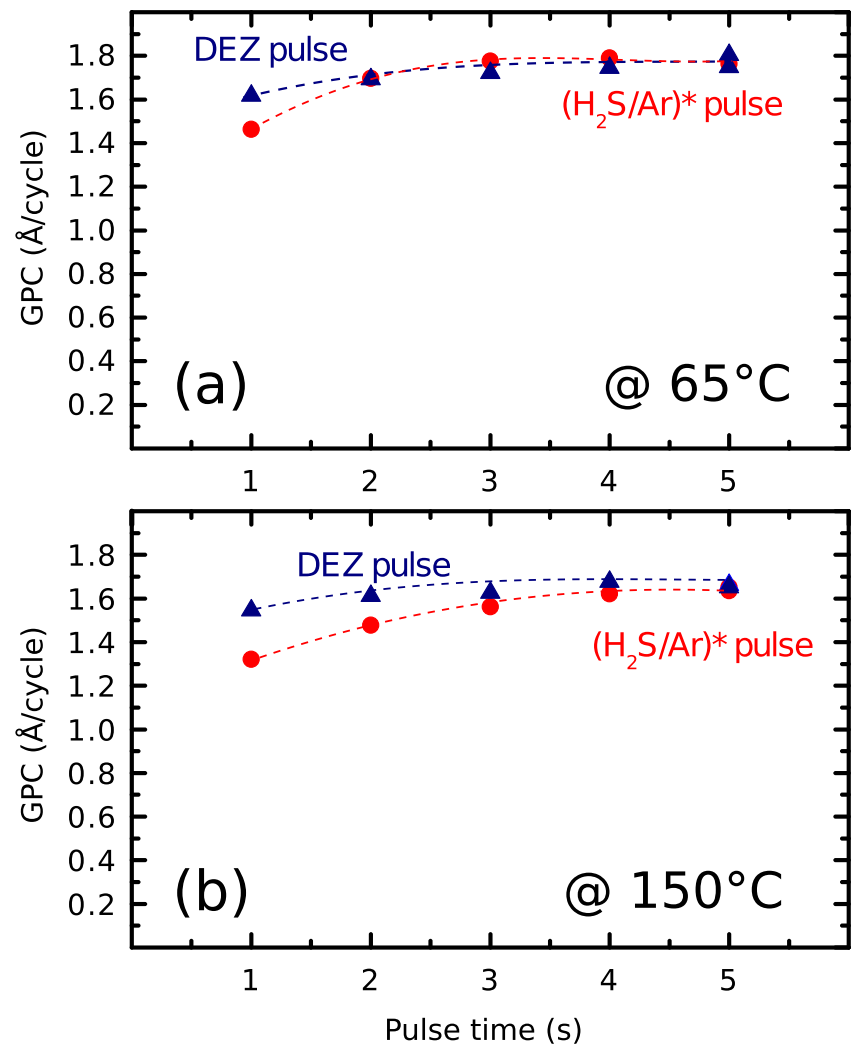

FIG. 3. (Color online) (a) Growth per cycle against the pulse time of DEZ and $\left(\mathrm{H}_{2} \mathrm{~S} / \mathrm{Ar}\right)^{*}$ for the PE-ALD ZnS process deposited at $65^{\circ} \mathrm{C}$. (b) Growth per cycle against the pulse time of DEZ and $\left(\mathrm{H}_{2} \mathrm{~S} / \mathrm{Ar}\right)^{*}$ for the PE-ALD process deposited at $150^{\circ} \mathrm{C}$. Dashed lines are a guide to the eye.

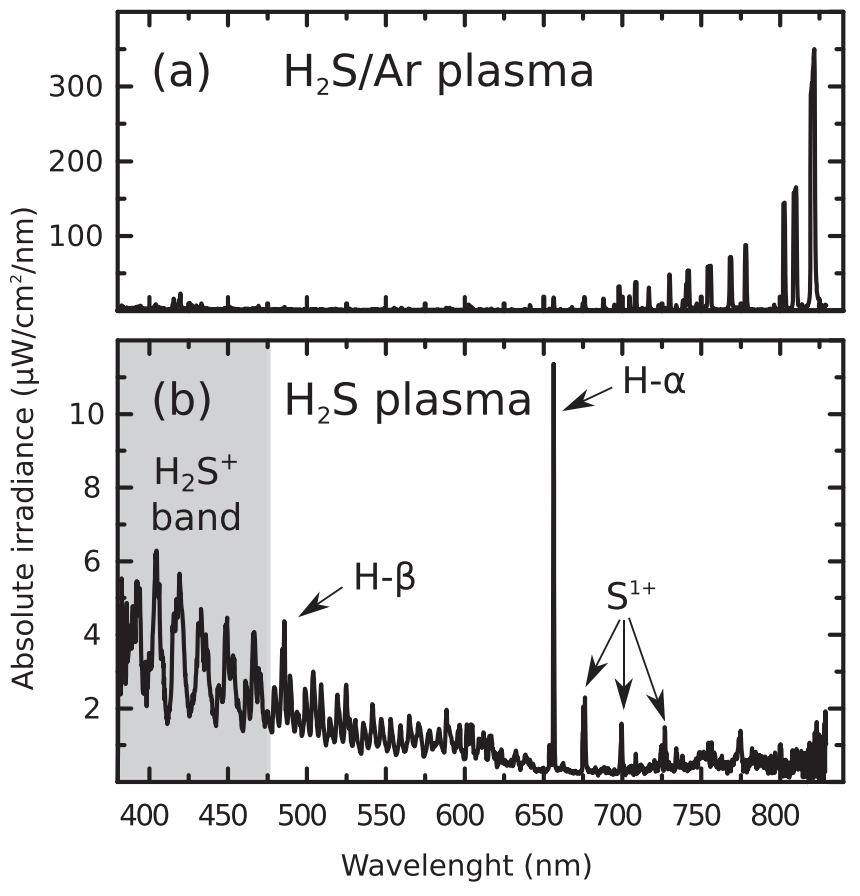

FIG. 4. Optical emission spectrum of (a) a $\mathrm{H}_{2} \mathrm{~S} / \mathrm{Ar}$ and (b) a pure $\mathrm{H}_{2} \mathrm{~S}$ plasma. Apart from the $\mathrm{H}_{2} \mathrm{~S}^{+}$molecular band, hydrogen and sulfur lines were also visible.

a molecular band with various peaks in the wavelength range from 370 to $475 \mathrm{~nm}$. This band was related to $\mathrm{H}_{2} \mathrm{~S}^{+} .{ }^{23,24}$ Furthermore, the spectrum contained hydrogen revealed by the $\mathrm{H}-\alpha$ and $\mathrm{H}-\beta$ peak from the Balmer series at 656.3 and $486.1 \mathrm{~nm}$, respectively. Finally, the spectrum showed indications of S with peaks around $660-730 \mathrm{~nm}$ which were identified with $\mathrm{S}^{1+} \cdot{ }^{25-27}$

It is known that elemental sulfur exists in various allotropes and that a $\mathrm{H}_{2} \mathrm{~S}$ or $\mathrm{H}_{2} \mathrm{~S} / \mathrm{Ar}$ plasma can form a large variety of sulfur-hydrogen species $\mathrm{S}_{x} \mathrm{H}_{y}$ with $\mathrm{x}$ up to 11 and $\mathrm{y}=0$ to $5 .^{28-30}$ Therefore, it is most likely that these species were also formed during our ALD process. Previous research on $\mathrm{H}_{2} \mathrm{~S}$ or $\mathrm{H}_{2} \mathrm{~S} / \mathrm{Ar}$ plasma showed that $\mathrm{S}_{2}$ can be detected at $260 \mathrm{~nm}$ in the optical emission spectrum ${ }^{28}$ and that $\mathrm{S}_{x} \mathrm{H}_{y}$ species with $x>2$ can be detected with mass spectrometry. ${ }^{30}$ In our setup, the detection of the $S_{2}$ peak in the optical emission spectrum was not possible due to the use of a plasma column made out of soda-lime glass instead of quartz glass. The used glass absorbed light below $300 \mathrm{~nm}$ did not allow for the detection of the $S_{2}$ peak at $260 \mathrm{~nm}$.

Finally, in situ mass spectrometry measurements were used to investigate the $\mathrm{H}_{2} \mathrm{~S} / \mathrm{Ar}$ plasma. In contrast to the results reported in the work of Ellmer, no $\mathrm{S}_{x} \mathrm{H}_{y}$ species with $x>1$ were found during our measurements. An explanation for this may be that Elmer collected and analyzed the ions coming directly from the plasma (direct line-of-sight) without any further ionization while our mass spectrometer was not in direct line-of-sight to the plasma. Furthermore, in our mass spectrometer, the ions from the plasma were first broken down by electron impact ionization and then analyzed. Therefore, all $\mathrm{S}_{x} \mathrm{H}_{y}$ species with $x>1$ which may have been formed in the plasma were most likely broken down into 
fragments in the mass spectrometer. In order to get more insights into the reaction mechanism of the PE-ALD $\mathrm{ZnS}$ process, in situ mass spectrometry measurements were done during a sequence of thermal and PE-ALD ZnS cycles. Since the partial pressure of $\mathrm{Ar}$ in the $\mathrm{H}_{2} \mathrm{~S} / \mathrm{Ar}$ plasma was too high to detect any reaction products, a pure $\mathrm{H}_{2} \mathrm{~S}$ plasma was used. Figure 5(a) shows the schematic diagram of the investigated ALD cycles. Three PE-ALD cycles were followed by three cycles of thermal ALD. Multiple ion detection mass spectrometry measurements were used to follow the evolution of specific mass-to-charge ratio $(\mathrm{m} / \mathrm{z})$ signals during these ALD cycles. The following precursors and potential reaction species were monitored: $\mathrm{H}_{2} \mathrm{~S}$ at $\mathrm{m} / z=34$, $\mathrm{CS}_{2}$ at $\mathrm{m} / z=76$, CS at $m / z=44$, and fragments of ethane $\left(\mathrm{C}_{2} \mathrm{H}_{6}\right)$ at $m / z=28$. Figure $5(\mathrm{~b})$ shows the partial pressure of the $\mathrm{H}_{2} \mathrm{~S}$ signal. It can be seen that the signal of $\mathrm{H}_{2} \mathrm{~S}$ coincided with the pulses of either $\mathrm{H}_{2} \mathrm{~S} / \mathrm{Ar}$ plasma or $\mathrm{H}_{2} \mathrm{~S}$. Figure 5 (c) shows the partial pressure of ions and molecules at $\mathrm{m} /$ $z=28$. This signal may originate either from fragments of DEZ (as it coincided with DEZ pulses) or from fragments of ethane, which is a reaction product of both half reactions in the thermal DEZ and $\mathrm{H}_{2} \mathrm{~S}$ ALD process. This signal was found during both types of processes suggesting that ligand exchange reactions are also taking place during PE-ALD. $\mathrm{CS}_{2}$ and $\mathrm{CS}$ are reaction products of a combustion-type reaction between DEZ and $\mathrm{H}_{2} \mathrm{~S}$. While no CS signal was

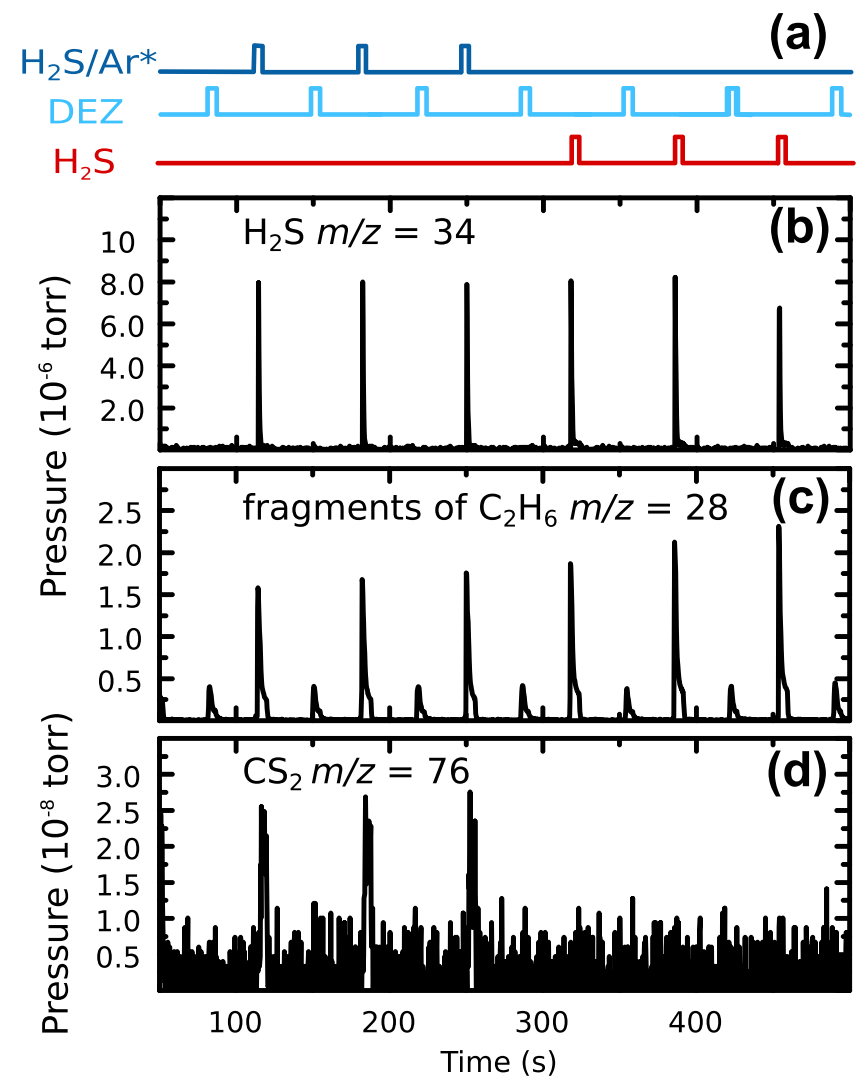

FIG. 5. (Color online) (a) Schematic diagram of the process sequences used during mass spectrometry. Partial pressure of (b) the $\mathrm{H}_{2} \mathrm{~S}$ signal at $m / z=34$, (c) the signal from fragments of ethane at $m / z=28$, and (d) the $\mathrm{CS}_{2}$ signal at $m / z=76$ derived from multiple ion detection mass spectrometry measurements during a sequence of thermal and PE-ALD ZnS cycles. detected, some $\mathrm{CS}_{2}$ was detected at a partial pressure of $10^{-8}$ Torr which is 2 orders of magnitude lower than $\mathrm{H}_{2} \mathrm{~S}$ and the ethane fragments [Fig. 5(d)]. However, it was only detected during the PE-ALD pulses and not during the thermal ALD. The presence of $\mathrm{CS}_{2}$ during the PE-ALD cycle may suggest that the PE-ALD process had some contribution of a combustion-type reaction.

\section{B. Material properties}

The material properties of $\mathrm{ZnS}$ deposited by PE-ALD were compared against the material properties of $\mathrm{ZnS}$ deposited with thermal ALD. Based on the results found during the ALD growth characterization, the main focus was put on intermediate deposition temperatures of approximately $150{ }^{\circ} \mathrm{C}$. In this region, the PE-ALD process has a potential advantage over the thermal process, as it offers a higher GPC. Furthermore, this temperature is compatible with most of the desired applications of $\mathrm{ZnS}^{6}$

XPS measurements were used to check the $\mathrm{ZnS}$ films for impurities. Figure 6 shows the XPS analysis of $\mathrm{ZnS}$ deposited by PE-ALD at 65 and $150^{\circ} \mathrm{C}$. The two upper survey spectra represent $\mathrm{PE}-\mathrm{ALD} \mathrm{ZnS}$ deposited at $150^{\circ} \mathrm{C}$ while the two lower represent PE-ALD ZnS deposited at $65^{\circ} \mathrm{C}$. It can be seen that the surface was oxidized and contaminated with carbon for both temperatures. After sputtering away some of the surface material, the oxygen and carbon content of the $\mathrm{ZnS}$ film was below the detection limit of approximately $1 \%$, indicating that a pure film without contamination was obtained. The $\mathrm{Zn}$ to $\mathrm{S}$ ratio was determined from the XPS spectra. Near-stoichiometric atomic ratios of 56:44 and 53:47 were found for the samples deposited at 65 and $150^{\circ} \mathrm{C}$, respectively. No excess of sulfur for lower temperature was found, showing that no condensation of sulfur occurred.

The crystallinity of $\mathrm{ZnS}$ thin films was investigated with XRD. Figure 7 shows the XRD pattern of the as-deposited $60 \mathrm{~nm}$ thick $\mathrm{ZnS}$ films deposited by thermal and PE-ALD at $80^{\circ} \mathrm{C}$. Both the thermal and PE-ALD ZnS films were already crystalline as deposited with mainly the zincblende phase growing along the [111] plane. Based on the full width half $\max$ of the main peak at $28.6^{\circ}$, it was estimated that $\mathrm{ZnS}$

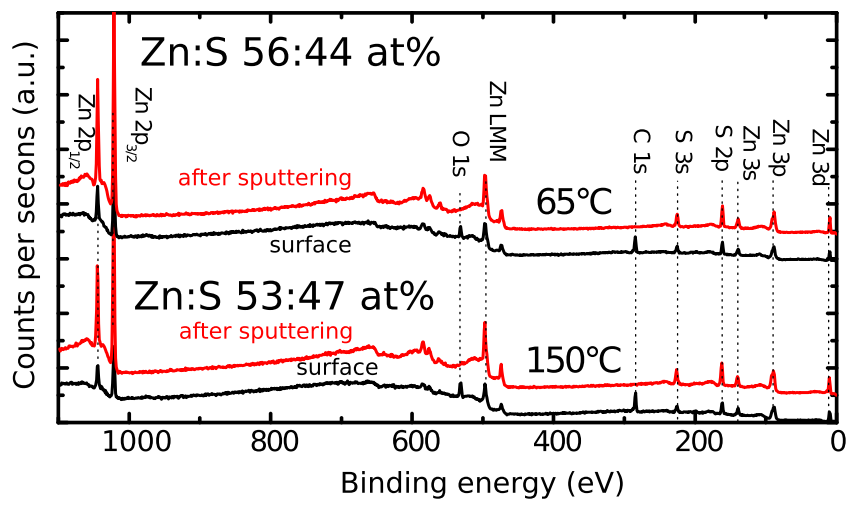

FIG. 6. (Color online) XPS survey spectra of PE-ALD ZnS deposited at 65 and $150^{\circ} \mathrm{C}$ before and after sputtering. 


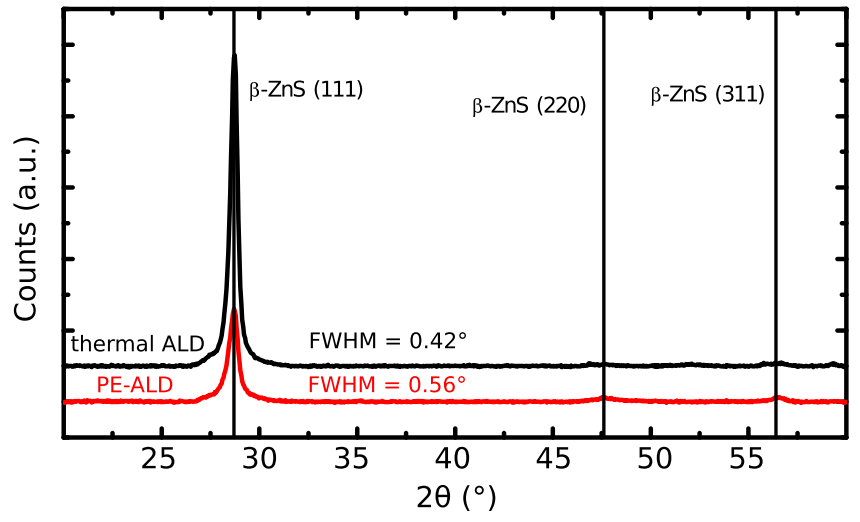

FIG. 7. (Color online) XRD pattern of as-deposited $60 \mathrm{~nm}$ thick $\mathrm{ZnS}$ films deposited by thermal and PE-ALD at $80^{\circ} \mathrm{C}$.

thin films deposited by PE-ALD had smaller grain sizes than ZnS films deposited with thermal ALD.

The optical properties of the as-deposited $\mathrm{ZnS}$ films were determined using optical transmittance measurements. An $11 \mathrm{~nm}$ (PE-ALD) and $15 \mathrm{~nm}$ (thermal ALD) thick ZnS film were deposited on a quartz substrate at $150^{\circ} \mathrm{C}$. The transmittance of these films is shown in the inset of Fig. 8. The films had an optical transmission of nearly $100 \%$ in the visible region, which is an important property for applications of $\mathrm{ZnS}$ as a TCL material or as an antireflective coating. To determine the band gap $\left(E_{g}\right)$ of the material, a Tauc$\operatorname{plot}^{16,31,32}$ was used, where $[\alpha(h \nu)]^{2}$ was plotted versus the photon energy (Fig. 8). The absorption coefficient $\alpha$ was calculated from the transmittance $T$ and the film thickness $d$, as $\alpha=\ln (T) / d$. Since $\mathrm{ZnS}$ has a direct band gap, it can be determined from the Tauc-plot by interpolation of the fit of the linear part of the absorption edge to zero. For the PE-ALD and thermal process, a band gap of 3.49 and $3.53 \mathrm{eV}$, respectively, was found. These values agree with the values reported in literature. ${ }^{33}$

The conformality of the ZnS coating on nonplanar substrates was studied by coating Si micropillars with $10 \mathrm{~nm}$ $\mathrm{ZnS}$ grown using thermal and PE-ALD. These Si micropillars had a width of $2 \mu \mathrm{m}$, height of $50 \mu \mathrm{m}$, and a center-tocenter spacing of $4 \mu \mathrm{m}$. ALD was done at $150^{\circ} \mathrm{C}$ using

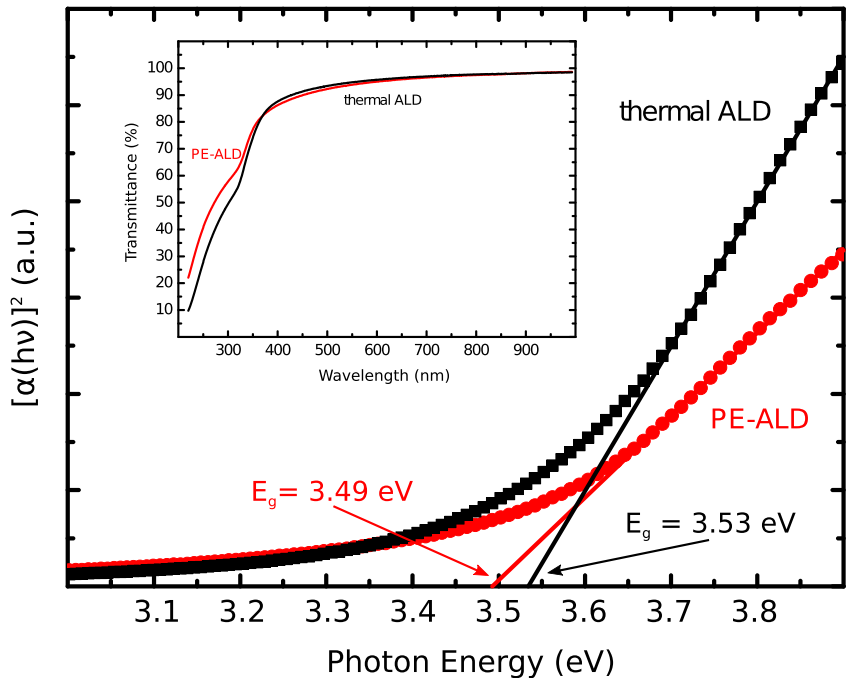

FIG. 8. (Color online) $[\alpha(\mathrm{h} \nu)]^{2}$ vs photon energy plot for an 11 and $15 \mathrm{~nm}$ thick ZnS thin film deposited with thermal and PE-ALD, respectively, on a quartz substrate at $150^{\circ} \mathrm{C}$. The band gap energy is determined from the linear fit to the absorption edge and by interpolation to zero as indicated. The inset of the figure shows the transmittance spectrum of the same films divided by the transmittance of the bare quartz substrate.

optimized deposition parameters with doubled precursor pulse times and purging times. Cross sections of these samples were investigated with SEM and EDX. Figure 9(b) shows the SEM cross section of micropillars coated with $10 \mathrm{~nm}$ PE-ALD ZnS. Since no contrast between the $\mathrm{ZnS}$ and $\mathrm{Si}$ was observed, various EDX line scans were performed at different positions along the micropillars [indicated by the vertical lines in Fig. 9(b)]. The total amount of deposited $\mathrm{ZnS}$ was estimated from the EDX scans [Fig. 9(a)] by integrating over the $\mathrm{Zn} \mathrm{L}$ peak. Figure 9(c) compares the amount of $\mathrm{Zn}$ at different depths along the pillars for samples coated with thermal and PE-ALD. Even at the bottom of the micropillars, more than $90 \% \mathrm{Zn}$ was found in comparison to the reference on top of the micropillars. By further optimizing the pulse and purge duration of each precursor, a conformal coating of larger aspect ratios should be possible.

AFM was used to study the morphology of $\mathrm{ZnS}$ films with increasing thickness from 10 to $36 \mathrm{~nm}$. From the AFM
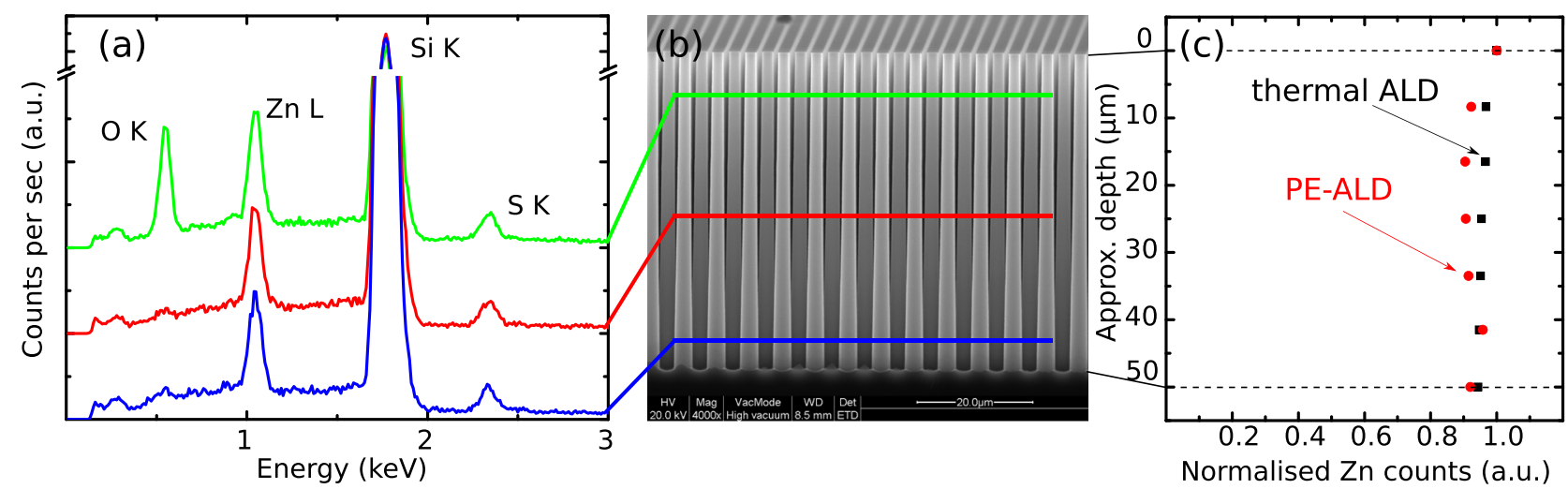

FIG. 9. (Color online) (a) EDX spectra obtained from line scans at different positions along the micropillars. (b) SEM cross section of Si micropillars coated with $10 \mathrm{~nm}$ PE-ALD ZnS. The horizontal lines indicated the positions of the EDX line scans. (c) Depth profile of deposited Zn along the micropillars obtained by integrating over the $\mathrm{Zn} \mathrm{L}$ peaks from the EDX spectra. The $\mathrm{Zn}$ counts are normalized to the $\mathrm{Zn}$ counts found on the top of the micropillars. 

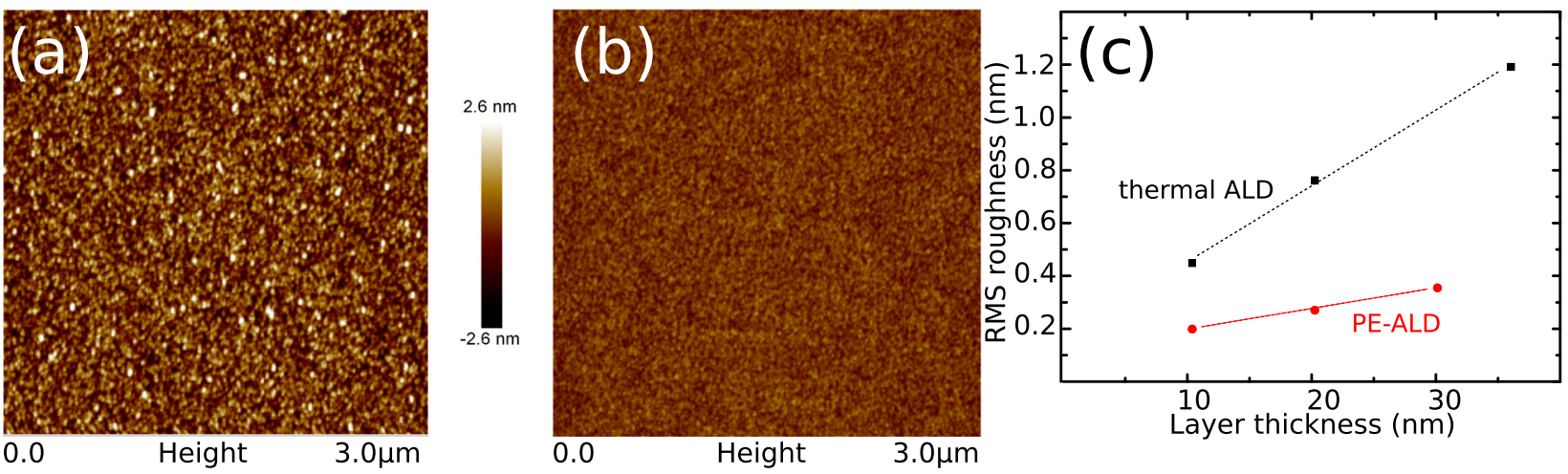

FIG. 10. (Color online) (a) AFM scan of $20 \mathrm{~nm}$ thermal ALD ZnS deposited at $150^{\circ} \mathrm{C}$ on $\mathrm{Si}$ covered with $100 \mathrm{~nm}$ thermally grown $\mathrm{SiO}{ }_{2}$. (b) $\mathrm{AFM}$ scan of $20 \mathrm{~nm}$ PE-ALD ALD $\mathrm{ZnS}$ deposited at $150^{\circ} \mathrm{C}$ on $\mathrm{Si}$ covered with $100 \mathrm{~nm}$ thermally grown $\mathrm{SiO}_{2}$. (c) RMS roughness of $\mathrm{ZnS}$ thin films as a function of the layer thickness. Dashed lines are a guide to the eye.

images, the RMS roughness was measured on area scans of $3 \times 3 \mu \mathrm{m}$. Figure 10 shows the AFM image of $20 \mathrm{~nm}$ thick ZnS films deposited at $150^{\circ} \mathrm{C}$ by (a) thermal ALD and (b) PE-ALD. It can be seen that $\mathrm{ZnS}$ thin films deposited by PEALD had a smoother surface than ZnS films deposited by thermal ALD. This may be explained by a smaller average grain size in ZnS films deposited by PE-ALD as indicated by XRD measurements. Figure 10(c) shows the RMS roughness as a function of the $\mathrm{ZnS}$ layer thickness. The thermal ALD process shows an increase in the RMS roughness for thicker $\mathrm{ZnS}$ layers which was already reported in previous works. ${ }^{16,20,34}$ The same trend was observed for the PE-ALD. For applications where a smooth $\mathrm{ZnS}$ interface is important such as CIGS solar cells, ${ }^{35}$ PE-ALD ZnS may have an advantage over thermal ALD ZnS.

\section{CONCLUSIONS}

A new plasma enhanced ALD ZnS process was developed using DEZ and $\mathrm{H}_{2} \mathrm{~S} / \mathrm{Ar}$ plasma. This process had a deposition window which was less temperature dependent than the deposition window of the thermal process which may lead to a better device integration or better matching of temperature windows for ALD of ternary compounds. ZnS films deposited by PE-ALD had similar optical and structural properties as $\mathrm{ZnS}$ thin films deposited by thermal ALD which was confirmed by XPS, XRD, and UV/Vis measurements. XPS studies confirmed the growth of $\mathrm{ZnS}$ without any detectable $\mathrm{O}$ or $\mathrm{C}$ contaminations. XRD revealed that the as-deposited films were already crystalline, making further annealing unnecessary. PE-ALD ZnS films showed a transmittance of more than $90 \%$ over the visible range, and the band gap was determined to be $3.49 \mathrm{eV}$. Conformal growth on micropillars was demonstrated. Finally, it was observed that $\mathrm{ZnS}$ deposited by PE-ALD has smoother surfaces in comparison to thermal ALD making this process potentially more attractive for solar cell application where a smooth interface is needed.

\section{ACKNOWLEDGMENTS}

J. Kuhs acknowledges the Agency for Innovation by Science and Technology (IWT) for a Ph.D. scholarship. T.
Dobbelaere acknowledges the FWO Vlaanderen for financial support through the mandate of Aspirant. The authors would like to acknowledge the financial support from the UGENTGOA-01G01513 and Hercules AUGE/09/014 projects. Finally, they would like to thank Karl Opsomer and Matthias Minjauw for XPS measurements and Olivier Janssens for SEM/EDX work.

${ }^{1}$ C. Platzer-Björkman, T. Törndahl, D. Abou-Ras, J. Malmström, J. Kessler, and L. Stolt, J. Appl. Phys. 100, 044506 (2006).

${ }^{2}$ E. Yousfi, T. Asikainen, V. Pietu, P. Cowache, M. Powalla, and D. Lincot, Thin Solid Films 361-362, 183 (2000).

${ }^{3}$ A. M. Diamond, L. Corbellini, K. R. Balasubramaniam, S. Chen, S. Wang, T. S. Matthews, L.-W. Wang, R. Ramesh, and J. W. Ager, Phys. Status Solidi 209, 2101 (2012).

${ }^{4}$ X. Xu et al., Nano Lett. 16, 1925 (2016).

${ }^{5}$ J. H. He, Y. Y. Zhang, J. Liu, D. Moore, G. Bao, and Z. L. Wang, J. Phys. Chem. C 111, 12152 (2007).

${ }^{6}$ X. Fang, T. Zhai, U. K. Gautam, L. Li, L. Wu, Y. Bando, and D. Golberg, Prog. Mater. Sci. 56, 175 (2011).

${ }^{7}$ R. L. Puurunen, J. Appl. Phys. 97, 121301 (2005).

${ }^{8}$ S. M. George, Chem. Rev. 110, 111 (2010).

${ }^{9}$ T. Suntola and J. Antson, U.S. patent 4,058,430 (25 November 1975).

${ }^{10}$ M. Pessa, R. Mäkelä, and T. Suntola, Appl. Phys. Lett. 38, 131 (1981).

${ }^{11}$ J. A. Lahtinen, A. Lu, T. Tuomi, and M. Tammenmaa, J. Appl. Phys. 58, 1851 (1985)

${ }^{12}$ D. Riihelä, M. Ritala, R. Matero, and M. Leskelä, Thin Solid Films 289, 250 (1996).

${ }^{13}$ J. Ihanus, M. P. Lankinen, M. Kemell, M. Ritala, and M. Leskelä, J. Appl. Phys. 98, 113526 (2005).

${ }^{14}$ N. P. Dasgupta, X. Meng, J. W. Elam, and A. B. F. Martinson, Acc. Chem. Res. 48, 341 (2015).

${ }^{15} \mathrm{G}$. Stuyven, P. De Visschere, A. Hikavyy, and K. Neyts, J. Cryst. Growth 234, 690 (2002).

${ }^{16}$ J. Bakke, J. King, H. Jung, R. Sinclair, and S. Bent, Thin Solid Films 518, $5400(2010)$

${ }^{17}$ J. T. Tanskanen, J. R. Bakke, S. F. Bent, and T. A. Pakkanen, Langmuir 26, 11899 (2010).

${ }^{18}$ J. T. Tanskanen, J. R. Bakke, T. A. Pakkanen, and S. F. Bent, J. Vac. Sci. Technol., A 29, 031507 (2011).

${ }^{19}$ C. D. Wagner, W. M. Riggs, L. E. Davis, and J. F. Moulder, Handbook of $X$-ray Photoelectron Spectroscopy (Perkin-Elmer Corporation, Eden Prairie, MN, 1979).

${ }^{20}$ Y. S. Kim and S. J. Yun, Appl. Surf. Sci. 229, 105 (2004).

${ }^{21}$ R. W. Johnson, A. Hultqvist, and S. F. Bent, Mater. Today 17, 236 (2014).

${ }^{22}$ H. B. Profijt, S. E. Potts, M. C. M. van de Sanden, and W. M. M. Kessels, J. Vac. Sci. Technol., A 29, 050801 (2011).

${ }^{23}$ R. Dixon, G. Duxbury, M. Horani, and J. Rostas, Mol. Phys. 22, 977 (1971).

${ }^{24}$ M. Toyoda, T. Ogawa, and N. Ishibashi, Bull. Chem. Soc. Jpn. 47, 95 (1974). 
${ }^{25}$ R. Frerichs, Z. Phys. 80, 150 (1933).

${ }^{26}$ O. Zatsarinny and K. Bartschat, J. Phys. B: At. Mol. Opt. Phys. 39, 2861 (2006).

${ }^{27}$ K. W. Meißner, O. Bartelt, and L. Eckstein, Z. Phys. 86, 54 (1933).

${ }^{28}$ A. J. Nelson, J. Vac. Sci. Technol., A 13, 1990 (1995).

${ }^{29}$ B. Meyer, Chem. Rev. 76, 367 (1976).

${ }^{30}$ K. Ellmer and D. Lichtenberger, Surf. Coat. Technol. 74-5, 586 (1995).
${ }^{31}$ J. Tauc, R. Grigorovici, and A. Vancu, Phys. Status Solidi 15, 627 (1966). ${ }^{32}$ J. Tauc, A. Menth, and D. L. Wood, Phys. Rev. Lett. 25, 749 (1970).

${ }^{33}$ W. H. Strehlow and E. L. Cook, J. Phys. Chem. Ref. Data 2, 163 (1973).

${ }^{34}$ J. Ihanus, M. Ritala, M. Leskela, T. Prohaska, R. Resch, G. Friedbacher, and M. Grasserbauer, Appl. Surf. Sci. 120, 43 (1997).

${ }^{35}$ W.-L. Liu, W.-J. Chen, S.-H. Hsieh, and J.-H. Yu, Procedia Eng. 36, 46 (2012). 